\title{
Establishment of Track Quality Index Standard Recommendations for Beijing Metro
}

\author{
Reng-Kui Liu, ${ }^{1}$ Peng Xu, ${ }^{1}$ Zhuang-Zhi Sun, ${ }^{2}$ Ce Zou, ${ }^{3}$ and Quan-Xin Sun ${ }^{1}$ \\ ${ }^{1}$ MOE Key Laboratory for Urban Transportation Complex Systems Theory and Technology, \\ Beijing Jiaotong University, Haidian District, Beijing 100044, China \\ ${ }^{2}$ Road Administration of Beijing Municipal Commission of Transport, Track Division, 317 Guang Nei Street, \\ Xuanwu District, Beijing 100053, China \\ ${ }^{3}$ Beijing Subway Operation Management Ltd., Subway Line Branch Company, Jia 5 De Sheng Men West Street, \\ Haidian District, Beijing 100082, China
}

Correspondence should be addressed to Peng Xu; xu.peng.bjtu@gmail.com

Received 18 July 2014; Revised 26 September 2014; Accepted 26 September 2014

Academic Editor: Wuhong Wang

Copyright (C) 2015 Reng-Kui Liu et al. This is an open access article distributed under the Creative Commons Attribution License, which permits unrestricted use, distribution, and reproduction in any medium, provided the original work is properly cited.

\begin{abstract}
Since 2007, Beijing Metro started to use track geometry car to measure quality of its tracks under wheel loading conditions. The track quality measurement data from the track geometry car were only used to assess local track quality by means of scoring $1000 \mathrm{~m}$ long track segments based on track exceptions. Track quality management experience of national railroads of China shows that, in addition to local track quality assessment, an overall track quality assessment method should be employed. The paper presented research results funded by Road Administration of Beijing Municipal Commission of Transport. The paper proposed an overall track quality assessment method for Beijing Metro and determined the overall track quality standards by means of a statistical method which was proposed in the paper. The standards are necessary for the proposed method to be applied and have been approved by Road Administration of Beijing Municipal Commission of Transport and put into practice.
\end{abstract}

\section{Introduction}

Metro systems prove to be an efficient transport mode to mitigate traffic congestion in metropolitan areas of large cities [1], for example, Beijing, Shanghai, New York city, Chicago, and so forth. The history in metro development in those developed countries dates back to over 100 years, whereas that in China began only 40 years ago [2]. The first metro line in China is line \#1 of Beijing and it commenced to serve passengers on October 1st, 1969 [2].

Advanced inspection instruments (e.g., track geometry car) were introduced to metro only within the recent 10 years [3]. For instance, Nanjing Metro started to use track geometry car on 2007 to measure quality of tracks under wheel loading conditions, and Beijing Metro introduced track geometry car into its track management practice also on 2007. Differently, Nanjing Metro's track geometry car was designed and manufactured by China Academy of Railway Science, whereas Beijing Metro's was imported from ENSCO INC. of USA.

Because these metro companies' exposure to track geometry car is for only several years, more reasonable use of data from these advanced inspection instruments is still under study [3]. For example, Beijing Metro only used data from its track geometry car to assess local track irregularity condition (i.e., track geometry exceptions). But experience of track condition management within national railroads of China shows that track condition management should be based on both local and overall quality assessment [4]. In other words, an overall track quality assessment method has to be developed for Beijing Metro. Considering this, Road Administration of Beijing Municipal Commission of Transport funded this research presented in this paper. 
The results of this research include a method to divide a metro track into track segments, a method for assessing the overall track quality of a track segment, and management standards of track quality index resulting from the overall track quality assessment method.

The rest of the paper is organized as follows. For better understanding of the paper, Section 2 gives definitions for these technical terms used in this paper. Existing overall track quality assessment methods are documented in Section 3. Based on characteristics of Beijing Metro tracks, Section 4 presents the developed overall track quality assessment method. Based on the track quality measurement data for the recent 3 years, Section 5 uses a statistic method to determine management standards of the track quality index resulting from the proposed assessment method. Remarks regarding the research in the paper and future research directions are concluded in Section 6.

\section{Track Quality Definitions}

Track quality is characterized by deviations of rail positions in a three-dimensional space from their designed ones in terms of gauge, cross level, left and right surface (usually called longitudinal level in European countries), left and right alignment, and twist [4-7]. Usually they are collectively referred to as track irregularities. In practice, track irregularities are measured with track geometry car, track geometry trolley, and some other manual tools. Track geometry car is used to measure irregularity condition of track under wheel loading conditions, whereas the other two kinds of instruments measure that of track without wheel loading on. In addition to track irregularity parameters, track geometry car simultaneously measures track response parameters to wheel loading such as vertical and lateral accelerations of car body and axle. The focus of the paper is on track irregularities measured with Beijing Metro track geometry car (hereafter is abbreviated as TGC-Beijing). Because of its unique characteristics compared with national rail tracks, Metro system usually has a third rail to supply electricity to metro trains. Consequently, TGC-Beijing also measures third rail geometry deviations including 3rd rail gauge and cross level. Additionally, TGC-Beijing has a rail profile measurement system.

During its inspection run at the speed of around 30$40 \mathrm{~km} / \mathrm{h}$, TGC-Beijing samples these three categories of condition parameters at an interval of $0.25 \mathrm{~m}$. In other words, there are 4000 sampling positions over a $1 \mathrm{~km}$ long track segment. Figure 1 shows an example of measurement data by TGC-Beijing. As mentioned in Section 1, measurement data from TGC-Beijing should be used to evaluate track condition with two different methods (i.e., local and overall quality assessment methods).

The local quality assessment method is based on track geometry exceptions that are described with quality parameter, position in $\mathrm{km}$ (i.e., milepoint) after which the quality parameter exceeds its lowest exception class limit, length in $\mathrm{m}$, maximum amplitude over the exception length, track position where the quality parameter takes the maximum amplitude value, and exception class (e.g., I, II, III, and IV)

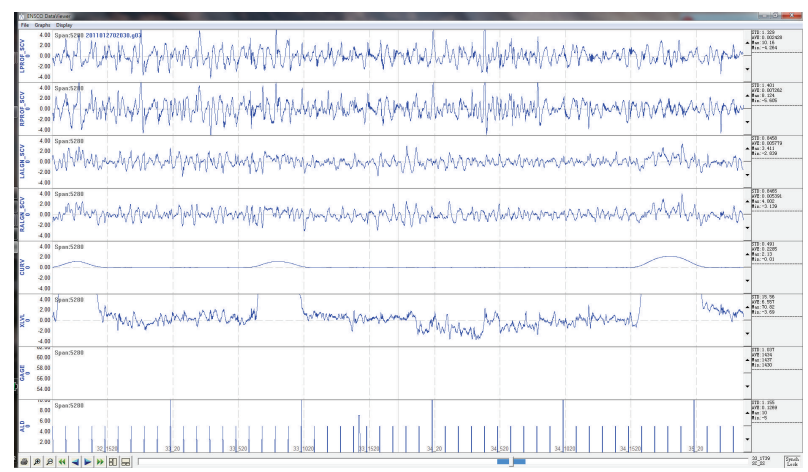

FIgURE 1: Measurement data example.

[4]. Those over a $1 \mathrm{~km}$ long track segment are summed up into a score based on weighting coefficients for exception classes. The higher the exception class, the larger the weighting coefficient.

The overall quality assessment method is based on statistics of all quality parameter measurement values over a track segment of a certain length which depends on track management and maintenance practices. Because these statistics are directly related to quality of a whole track segment, they are usually referred to as track quality index. Section 3 will document most of those existing track quality indices.

\section{Existing Track Quality Indices}

There are mainly eight statistics being adopted throughout the world to assess track quality of a whole track segment [3].

3.1. SD Index. SD index consists of seven standard deviations $\left\{\sigma_{i}, \forall i=1,2, \ldots, 7\right\}$, each of which is associated with a track quality parameter and is calculated from measurement values for the parameter over a track segment, as formulated in (1). The larger the SD index is, the worse the track segment is in some aspect represented with the quality parameter. Consider

$$
\begin{gathered}
\sigma_{i}=\sqrt{\frac{1}{n} \sum_{j=1}^{n}\left(x_{i j}^{2}-\bar{x}_{i}^{2}\right),} \\
\bar{x}_{i}=\sum_{j=1}^{n} \frac{x_{i j}}{n},
\end{gathered}
$$

where $\sigma_{i}$ is the standard deviation of a quality parameter in $\mathrm{mm}, x_{i j}$ the measurement value in $\mathrm{mm}$ for the parameter at the $j$ th sampling point in the track segment, and $n$ the number of sampling points in the track segment.

Track quality indices of United Kingdom, Australia, and so forth are like the SD indices. Differently, they apply (1) to different lengths of track segments.

3.2. Q Index. ProRail of Netherlands converts the SD index into a more universal form across different classes of tracks, as shown in (2) (where $N$ denotes the Q index for a quality parameter over a $200 \mathrm{~m}$ long track segment, $\sigma_{i}$ is the standard deviation for the quality parameter, and $\sigma_{i}^{80}$ represents the 
80th percentile of standard deviations for $200 \mathrm{~m}$ long segments in a maintenance section ranging in length from 5 to $10 \mathrm{~km}$ ). The $\mathrm{Q}$ index ranges from 10 to 0 . The larger the $\mathrm{Q}$ index, the better the track quality of a $200 \mathrm{~m}$ long track segment. Consider

$$
N=10 * 0.675^{\sigma_{i} / \sigma_{i}^{80}} .
$$

3.3. $P$ Index. $\mathrm{P}$ index is adopted by Japanese railroads and is the ratio of the number of sampling points whose quality parameter measurements fall outside $\pm 3 \mathrm{~mm}$ to the number of all sampling points in a track segment. There are two lengths of track segments over which $\mathrm{P}$ index is applied, $100 \mathrm{~m}$ and $500 \mathrm{~m}$. The larger the $\mathrm{P}$ index, the worse the track segment in some quality aspect.

3.4. Track Roughness Index. Track roughness index was proposed in 1998 by America Amtrak. It is the average of squared measurement values for a quality parameter over a track segment, as shown in

$$
\mathrm{TRI}_{i}=\sum_{j=1}^{n} \frac{\left(x_{i j}\right)^{2}}{n}
$$

3.5. Track Geometry Index. Track geometry index $\mathrm{TGI}_{i}$ uses the measurement value space curve length $L_{i}$ for a quality parameter over a track segment to quantify the quality of the track segment, as shown in (4). A larger $\mathrm{TGI}_{i}$ indicates that the track segment has a worse quality. Consider

$$
\begin{gathered}
\mathrm{TGI}_{i}=\left(\frac{L_{i}}{L_{0}}-1\right) * 10^{6} \\
L_{i}=\sum_{j=1}^{n-1} \sqrt{\left(x_{i(j+1)}-x_{i j}\right)^{2}+\left(y_{j+1}-y_{j}\right)^{2}},
\end{gathered}
$$

where $L_{i}$ is the measurement value space curve length for a quality parameter over a track segment, $L_{0}$ the length of the track segment, and $y_{j}$ the milepoint of the $j$ th sampling point on the track segment.

3.6. CN's Track Quality Index. Canadian National Railway Company $(\mathrm{CN})$ uses a 2 nd order polynomial equation of the standard deviation $\sigma_{i}$ of measurement values for a quality parameter over a track segment to assess its partial quality, as formulated in (5) (where $C$ is a constant and takes on the value of 700 for the main line tracks). The overall quality assessment is achieved by averaging six partial quality indices for gauge, cross level, left (right) surface, and left (right) alignment. Consider

$$
\mathrm{TQI}_{i}=1000-C * \sigma_{i}^{2}
$$

A larger track quality index implies the track segment has a better quality.
3.7. SNCF's Mean Deviation Indices. SNCF's indices are different from the above introduced indices. They are not based on standard deviations but on weighted moving average over a track segment, as illustrated in

$$
T L^{i}\left(y_{0}\right)=\frac{1}{300} \int_{-\infty}^{y_{0}} \eta^{i}(y) \exp \left(\frac{y-y_{0}}{300}\right) d y,
$$

where $y_{0}$ is the maximum milepoint value in the track segment and $\eta^{i}(y)$ the measurement data for a quality parameter at the milepoint $y$.

3.8. Chinese Track Quality Index. Like SD index, both national railroads and Nanjing Metro in China mainland use the sum of standard deviations of seven quality parameters to assess the overall track quality of a track segment, as formulated in (7). There are two lengths for the overall track quality assessment, $200 \mathrm{~m}$ and $500 \mathrm{~m}$. The track length of $500 \mathrm{~m}$ is applied to high-speed railroads. Of course, the track length of $200 \mathrm{~m}$ is at the same time adopted for track segment quality assessment. The larger the value of TQI, the worse the track segment in the overall track quality. Consider

$$
\begin{gathered}
\text { TQI }=\sum_{i=1}^{7} \sigma_{i} \\
\sigma_{i}=\sqrt{\frac{1}{n} \sum_{j=1}^{n}\left(x_{i j}^{2}-\bar{x}_{i}^{2}\right)} \\
\bar{x}_{i}=\sum_{j=1}^{n} \frac{x_{i j}}{n} .
\end{gathered}
$$

\section{Track Quality Index for Beijing Metro}

Track quality index is intended to guide mechanized maintenance. That means establishing a track quality index for Beijing Metro has to accord with its track characteristics and mechanized maintenance practice.

4.1. Track Characteristics of Beijing Metro. There are three main characteristics distinguishing metro tracks and railroad tracks. The first one is that metro tracks are more sharply curved than the counterpart. As shown in Tables 1 and 2, compared with the allowable minimum curve radius for class I and II railroad tracks, metro tracks have much sharper allowable curves. Secondly, curved tracks constitute about $1 / 3$ of Beijing Metro tracks, whereas the curved track length for national railroads of China only is only 24.56 percent of the total mileage. Finally, the operational speed on Beijing Metro tracks is extremely different from that on national railroads. The operational speed is around $40 \mathrm{~km} / \mathrm{h}$ for metro trains, whereas the operational speed for existing normal speed railroads is far over $60 \mathrm{~km} / \mathrm{h}$. Therefore, Beijing Metro's track quality index has to be established according to its own management and maintenance practices. And it is unreasonable to borrow the overall track quality standards from both national railroads and other metro companies. 
TABLE 1: The allowable minimum curve radius for class I and II railroad tracks shared by passenger and freight trains [8].

\begin{tabular}{lcccccc}
\hline \multicolumn{2}{c}{ Permissible travelling speed $(\mathrm{km} / \mathrm{h})$} & 160 & 140 & 120 & 100 & 80 \\
\hline \multirow{2}{*}{ Surrounding conditions } & General & 2000 & 1600 & 1200 & 800 & 600 \\
& Difficult & 1600 & 1200 & 800 & 600 & 500 \\
\hline
\end{tabular}

TABLE 2: The allowable minimum curve radius on metro tracks [9].

\begin{tabular}{lcccc}
\hline \multirow{2}{*}{ Track category } & \multicolumn{2}{c}{ General conditions } & \multicolumn{2}{c}{ Difficult conditions } \\
& Trains of group A & Trains of group B & Trains of group A & Trains of group B \\
\hline Main line & & & 300 & 250 \\
$V \leq 80 \mathrm{~km} / \mathrm{h}$ & 350 & 500 & 450 & 400 \\
$\quad 50 \mathrm{~km} / \mathrm{h} \leq V \leq 100 \mathrm{~km} / \mathrm{h}$ & 550 & 200 & 150 \\
Connection and siding tracks & 250 & 110 & 110 \\
Yard tracks & 150 & & & \\
\hline
\end{tabular}

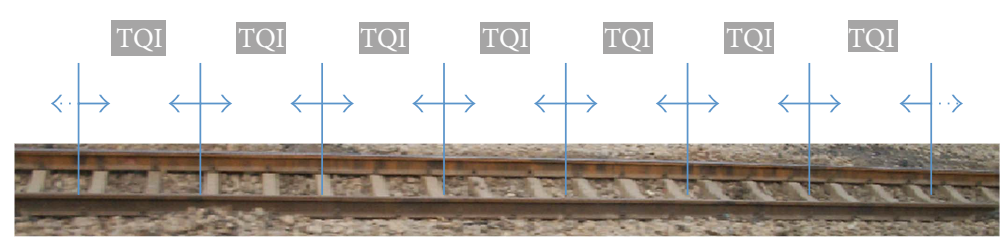

FIGURE 2: Procedure of splitting a track into consecutive $200 \mathrm{~m}$ long segments.

4.2. Establishment of Track Quality Index for Beijing Metro. Section 3.8 shows that by now although metros of China do not develop their own track quality index for the overall track quality assessment, Nanjing Metro's practices in using the national railroads' track quality index for the last six years give us some help. The overall track quality assessment method (i.e., Section 3.8) extensively adopted within national railroads is capable of accomplishing the overall track quality assessment task for metros of China; however they have to establish their own standards.

What is more, experts from Beijing Metro, Beijing MTR, and China Railway Corporation were invited together on December 12th, 2012, to share their knowledge regarding track maintenance management. Because track quality quantities calculated according to the extensively adopted method are intuitive and are convenient for railroaders to manage track quality. They all suggested adopting the method to assess the overall track quality of track segments. The length of track segments was suggested to be $200 \mathrm{~m}$.

The application of the proposed method consists of two steps. The first is to split a track of interest into consecutive $200 \mathrm{~m}$ long track segments, as shown in Figure 2. The second is to calculate track quality quantities from track quality measurement data collected by TGC-Beijing. This requires that milepoint measurements of those track quality measurement data have to be fair accurate. Our methods in [10, 11] were successively used to process the track quality measurement data before they are used to calculate track quality quantities.

\section{Recommended Track Quality Standards}

The track quality measurement data collected by TGCBeijing after its upgrade on May of 2010 were all gathered and were processed with the methods in [10-12]. This section will use all those track quality quantities to determine track quality standard recommendations associated with the adopted method for Beijing Metro.

5.1. The Method for Determining Track Quality Standard Recommendations. As mentioned in Section 3, the overall track quality assessment is mainly used to schedule mechanized track maintenance. Therefore, a better way to determine track quality standard recommendations is based on available maintenance resources (i.e., how long track could Beijing Metro each year conduct mechanized maintenance on?). The distribution of track quality quantities for each quality parameter over each metro track or over all metro tracks is useful for track quality standard determination based on available maintenance resources.

Figure 3 shows distributions of track quality quantities for five quality parameters over all metro tracks. Left and right surface standard deviations are treated together as surface ones and plotted on Figure 3(b). The same procedure is applied to left and right alignment standard deviations. In addition to the distributions for all metro tracks as a whole, these distributions over each metro track are also plotted. All these distributions will be used in the following section to determine track quality standard recommendations. 


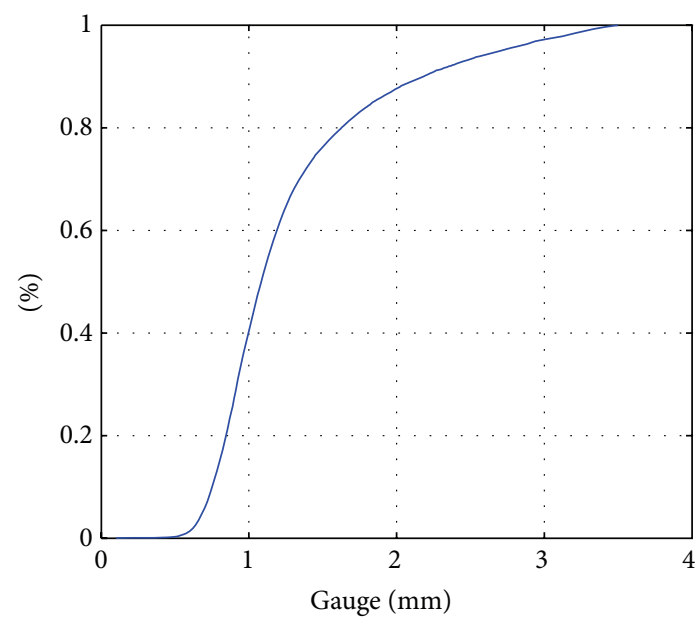

(a) Gauge

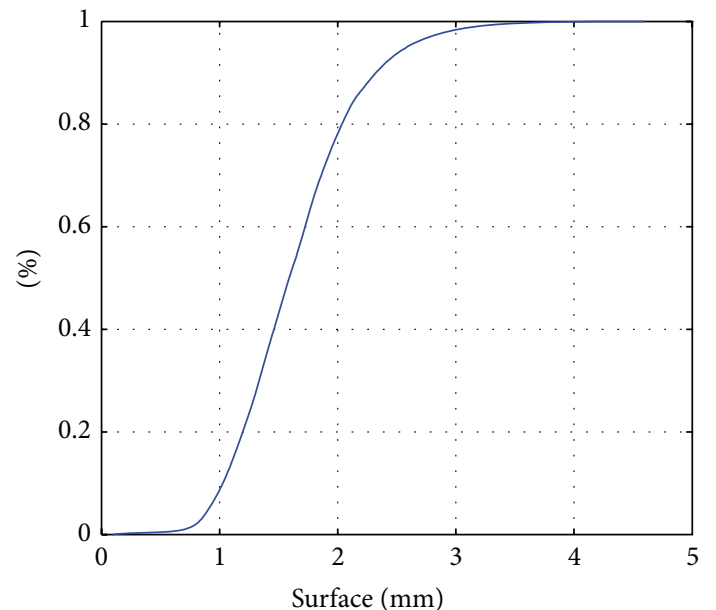

(c) Surface

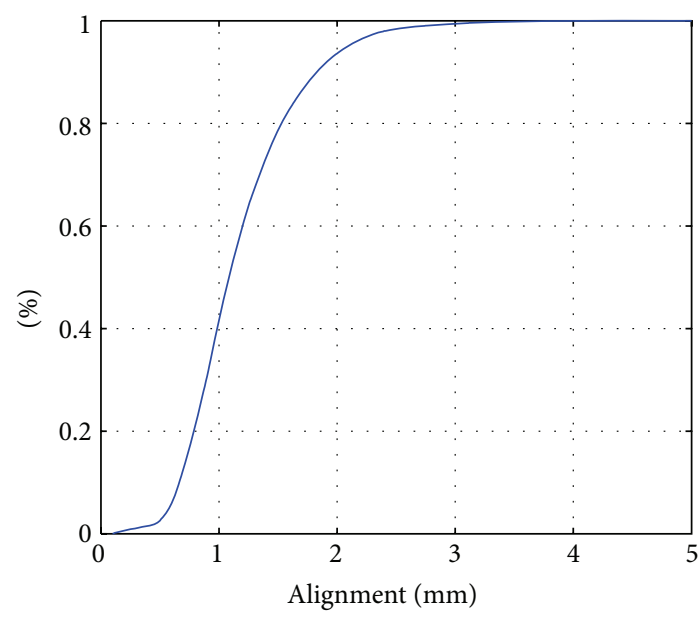

(b) Alignment

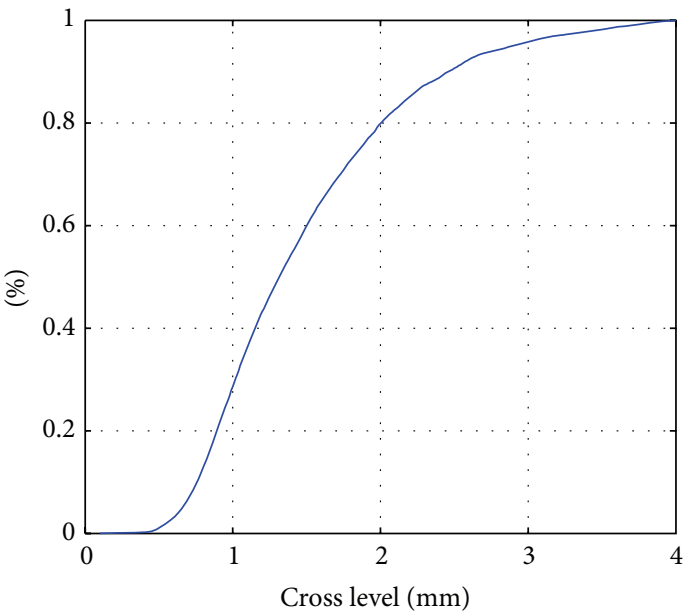

(d) Cross level

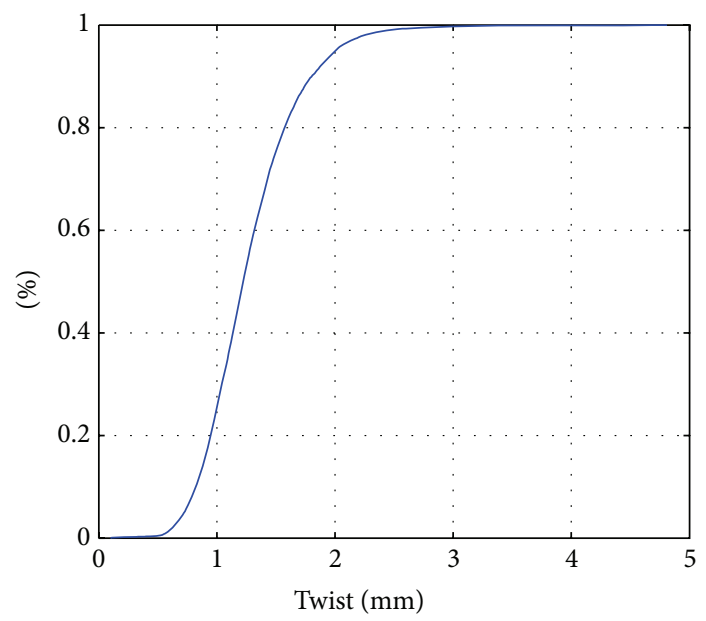

(e) Twist

FIGURE 3: Distributions of track quality quantities for track quality parameters. 
TABLE 3: The 70th percentiles of track quality quantities over each track.

\begin{tabular}{|c|c|c|c|c|c|c|c|}
\hline$\#$ & Track & Surface & Alignment & Gauge & Cross level & Twist & TQI \\
\hline 1 & 10\# right & $2.20 \times 2$ & $2.09 \times 2$ & 1.31 & 1.80 & 1.49 & 13.19 \\
\hline 2 & 10\# left & $2.07 \times 2$ & $1.99 \times 2$ & 1.17 & 1.60 & 1.23 & 12.12 \\
\hline 3 & East 13\# upgoing & $2.13 \times 2$ & $1.49 \times 2$ & 1.15 & 1.74 & 1.61 & 11.72 \\
\hline 4 & East 13\# downgoing & $2.03 \times 2$ & $1.56 \times 2$ & 1.08 & 1.40 & 1.32 & 10.97 \\
\hline 5 & West 13\# upgoing & $2.20 \times 2$ & $1.91 \times 2$ & 1.50 & 1.76 & 1.42 & 12.90 \\
\hline 6 & West 13\# downgoing & $2.05 \times 2$ & $1.64 \times 2$ & 1.40 & 1.78 & 1.36 & 11.92 \\
\hline 7 & 1\# upgoing & $2.37 \times 2$ & $2.19 \times 2$ & 1.59 & 1.54 & 1.55 & 13.81 \\
\hline 8 & 1\# downgoing & $2.61 \times 2$ & $2.08 \times 2$ & 1.55 & 1.67 & 1.69 & 14.29 \\
\hline 9 & 2\# inner circle & $2.29 \times 2$ & $2.06 \times 2$ & 1.65 & 2.64 & 1.82 & 14.79 \\
\hline 10 & 2\# outer circle & $2.02 \times 2$ & $2.26 \times 2$ & 1.63 & 2.56 & 1.63 & 14.38 \\
\hline 11 & 5\# upgoing & $1.84 \times 2$ & $2.12 \times 2$ & 1.14 & 1.43 & 1.28 & 11.77 \\
\hline 12 & 5\# downgoing & $2.00 \times 2$ & $2.24 \times 2$ & 1.14 & 1.52 & 1.27 & 12.41 \\
\hline 13 & Ba-Tong upgoing & $2.27 \times 2$ & $1.68 \times 2$ & 1.26 & 1.36 & 1.09 & 11.61 \\
\hline 14 & Ba-Tong downgoing & $2.38 \times 2$ & $1.85 \times 2$ & 1.28 & 1.36 & 1.21 & 12.31 \\
\hline
\end{tabular}

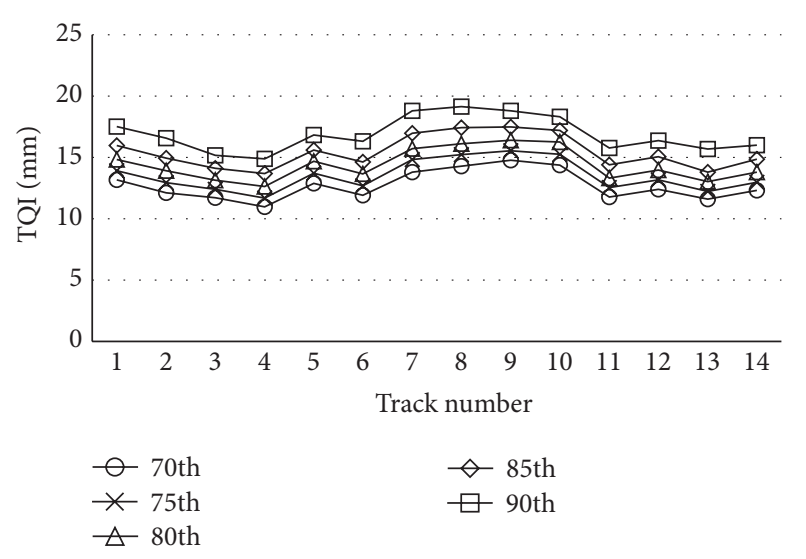

FIGURE 4: Five percentiles of TQIs for all metro tracks.

5.2. Track Quality Quantities. Five percentiles (70th, 75th, 80th, 85th, and 90th) of track quality quantities for the five parameters over each metro track are obtained according to distributions like those on Figure 3 and are tabulated in Tables $3,4,5,6$, and 7 , respectively.

Beijing Metro set up a project department for each metro line (including two tracks) to perform routine inspection and maintenance and to coordinate with the mechanized maintenance department. The percentiles in Tables 3-7 are helpful for project departments to schedule routine inspection and maintenance.

TQI values at a given percentile for the 14 metro tracks are plotted on Figure 4. It is clear that different tracks have different TQI values for a given percentile (i.e., track managers have the same percentage of maintenance resources available to all metro tracks). But from the perspective of maintenance resource allocation, Beijing Metro would like to allocate resources based on the quality of each track in order to keep the 14-track balance in track quality. Therefore, those percentiles for the five parameters over all the tracks as a whole are calculated and tabulated in Table 8 .
5.3. Track Quality Standard Recommendations. We consulted Beijing Metro's experts and track managers from Beijing Municipal Commission of Transport about available maintenance resources. Each year Beijing Metro can only carry out mechanized maintenance on 20 percent of its track length. Therefore, the 80th percentiles (i.e., Table 5 and the third row in Table 8) will be reasonable and acceptable track quality standard recommendations associated with the presented track quality index for Beijing Metro.

\section{Conclusions and Future Research Directions}

Since 2007 Beijing Metro started to use track geometry car (TGC-Beijing) to measure quality of its tracks under wheel loading conditions. After each inspection run of TGCBeijing's, measurement data are only used to assess local track quality by means of scoring $1 \mathrm{~km}$ long track segments based on track exceptions (as detailed in Section 2). Track quality measurement experience from national railroads of China shows that, in addition to local track quality assessment, overall track quality assessment has also to be employed. Differently from local track quality assessment, this kind of assessment is based on all measurement data over the track segment of interest. But no such assessment method is available for Beijing Metro.

The research presented in the paper was funded by Road Administration of Beijing Municipal Commission of Transport to propose an overall track quality assessment method and to establish the corresponding management standards so that the research results can be applicable. This paper documented those extensively used overall track quality assessment methods throughout the world. Based on Nanjing Metro's practices in applying track quality index of national railroads, and experience of experts from Beijing Metro and China Railway Corporation, an overall track quality assessment method is chosen for Beijing Metro. A statistical method was proposed to determine the overall track quality standards associated with the method. Based 
TABLE 4: The 75th percentiles of track quality quantities over each track.

\begin{tabular}{|c|c|c|c|c|c|c|c|}
\hline$\#$ & Track & Surface & Alignment & Gauge & Cross level & Twist & TQI \\
\hline 1 & 10\# right & $2.31 \times 2$ & $2.23 \times 2$ & 1.41 & 1.88 & 1.55 & 13.92 \\
\hline 2 & $10 \#$ left & $2.18 \times 2$ & $2.14 \times 2$ & 1.28 & 1.72 & 1.32 & 12.95 \\
\hline 3 & East 13\# upgoing & $2.23 \times 2$ & $1.59 \times 2$ & 1.25 & 1.83 & 1.69 & 12.40 \\
\hline 4 & East 13\# downgoing & $2.14 \times 2$ & $1.67 \times 2$ & 1.18 & 1.53 & 1.36 & 11.70 \\
\hline 5 & West 13\# upgoing & $2.31 \times 2$ & $2.02 \times 2$ & 1.68 & 1.88 & 1.50 & 13.72 \\
\hline 6 & West 13\# downgoing & $2.16 \times 2$ & $1.75 \times 2$ & 1.51 & 1.92 & 1.44 & 12.69 \\
\hline 7 & 1\# upgoing & $2.51 \times 2$ & $2.32 \times 2$ & 1.70 & 1.83 & 1.65 & 14.83 \\
\hline 8 & 1\# downgoing & $2.75 \times 2$ & $2.22 \times 2$ & 1.65 & 1.86 & 1.78 & 15.23 \\
\hline 9 & 2\# inner circle & $2.38 \times 2$ & $2.16 \times 2$ & 1.78 & 2.81 & 1.88 & 15.55 \\
\hline 10 & 2\# outer circle & $2.11 \times 2$ & $2.39 \times 2$ & 1.80 & 2.74 & 1.72 & 15.25 \\
\hline 11 & 5\# upgoing & $1.95 \times 2$ & $2.26 \times 2$ & 1.30 & 1.50 & 1.34 & 12.55 \\
\hline 12 & 5\# downgoing & $2.13 \times 2$ & $2.38 \times 2$ & 1.22 & 1.61 & 1.34 & 13.19 \\
\hline 13 & Ba-Tong upgoing & $2.39 \times 2$ & $1.78 \times 2$ & 1.33 & 1.44 & 1.14 & 12.24 \\
\hline 14 & Ba-Tong downgoing & $2.50 \times 2$ & $1.98 \times 2$ & 1.35 & 1.43 & 1.25 & 12.99 \\
\hline
\end{tabular}

TABLE 5: The 80th percentiles of track quality quantities over each track.

\begin{tabular}{|c|c|c|c|c|c|c|c|}
\hline$\#$ & Track & Surface & Alignment & Gauge & Cross level & Twist & TQI \\
\hline 1 & 10\# right & $2.45 \times 2$ & $2.37 \times 2$ & 1.63 & 1.93 & 1.65 & 14.83 \\
\hline 2 & $10 \#$ left & $2.30 \times 2$ & $2.28 \times 2$ & 1.53 & 1.85 & 1.38 & 13.92 \\
\hline 3 & East 13\# upgoing & $2.33 \times 2$ & $1.68 \times 2$ & 1.40 & 1.94 & 1.78 & 13.15 \\
\hline 4 & East 13\# downgoing & $2.25 \times 2$ & $1.79 \times 2$ & 1.47 & 1.65 & 1.42 & 12.64 \\
\hline 5 & West 13\# upgoing & $2.41 \times 2$ & $2.17 \times 2$ & 1.78 & 2.13 & 1.62 & 14.68 \\
\hline 6 & West 13\# downgoing & $2.28 \times 2$ & $1.88 \times 2$ & 1.76 & 2.02 & 1.55 & 13.65 \\
\hline 7 & 1\# upgoing & $2.64 \times 2$ & $2.44 \times 2$ & 1.82 & 1.96 & 1.77 & 15.71 \\
\hline 8 & 1\# downgoing & $2.91 \times 2$ & $2.33 \times 2$ & 1.78 & 1.95 & 1.89 & 16.11 \\
\hline 9 & 2\# inner circle & $2.47 \times 2$ & $2.26 \times 2$ & 2.00 & 3.00 & 1.95 & 16.42 \\
\hline 10 & 2\# outer circle & $2.19 \times 2$ & $2.52 \times 2$ & 2.19 & 2.89 & 1.76 & 16.26 \\
\hline 11 & 5\# upgoing & $2.06 \times 2$ & $2.40 \times 2$ & 1.45 & 1.59 & 1.38 & 13.33 \\
\hline 12 & 5\# downgoing & $2.25 \times 2$ & $2.53 \times 2$ & 1.30 & 1.70 & 1.41 & 13.97 \\
\hline 13 & Ba-Tong upgoing & $2.51 \times 2$ & $1.88 \times 2$ & 1.46 & 1.62 & 1.18 & 13.04 \\
\hline 14 & Ba-Tong downgoing & $2.61 \times 2$ & $2.12 \times 2$ & 1.46 & 1.55 & 1.32 & 13.80 \\
\hline
\end{tabular}

TABLE 6: The 85th percentiles of track quality quantities over each track.

\begin{tabular}{|c|c|c|c|c|c|c|c|}
\hline$\#$ & Track & Surface & Alignment & Gauge & Cross level & Twist & TQI \\
\hline 1 & 10\# right & $2.57 \times 2$ & $2.52 \times 2$ & 1.97 & 2.06 & 1.80 & 15.99 \\
\hline 2 & 10\# left & $2.42 \times 2$ & $2.40 \times 2$ & 1.85 & 1.99 & 1.47 & 14.96 \\
\hline 3 & East $13 \#$ upgoing & $2.46 \times 2$ & $1.79 \times 2$ & 1.75 & 2.03 & 1.86 & 14.13 \\
\hline 4 & East 13\# downgoing & $2.40 \times 2$ & $1.92 \times 2$ & 1.72 & 1.81 & 1.53 & 13.69 \\
\hline 5 & West 13\# upgoing & $2.52 \times 2$ & $2.28 \times 2$ & 1.97 & 2.29 & 1.75 & 15.62 \\
\hline 6 & West 13\# downgoing & $2.39 \times 2$ & $2.01 \times 2$ & 2.04 & 2.13 & 1.67 & 14.63 \\
\hline 7 & 1\# upgoing & $2.77 \times 2$ & $2.57 \times 2$ & 2.02 & 2.38 & 1.91 & 16.99 \\
\hline 8 & 1\# downgoing & $3.12 \times 2$ & $2.47 \times 2$ & 1.97 & 2.24 & 2.04 & 17.44 \\
\hline 9 & 2\# inner circle & $2.57 \times 2$ & $2.37 \times 2$ & 2.30 & 3.24 & 2.08 & 17.50 \\
\hline 10 & 2\# outer circle & $2.28 \times 2$ & $2.66 \times 2$ & 2.43 & 3.08 & 1.81 & 17.20 \\
\hline 11 & 5\# upgoing & $2.19 \times 2$ & $2.55 \times 2$ & 1.76 & 1.72 & 1.47 & 14.41 \\
\hline 12 & 5\# downgoing & $2.38 \times 2$ & $2.70 \times 2$ & 1.53 & 1.86 & 1.52 & 15.06 \\
\hline 13 & Ba-Tong upgoing & $2.64 \times 2$ & $1.99 \times 2$ & 1.62 & 1.72 & 1.23 & 13.82 \\
\hline 14 & Ba-Tong downgoing & $2.77 \times 2$ & $2.30 \times 2$ & 1.63 & 1.69 & 1.42 & 14.86 \\
\hline
\end{tabular}


TABLE 7: The 90th percentiles of track quality quantities over each track.

\begin{tabular}{|c|c|c|c|c|c|c|c|}
\hline$\#$ & Track & Surface & Alignment & Gauge & Cross level & Twist & TQI \\
\hline 1 & 10\# right & $2.72 \times 2$ & $2.71 \times 2$ & 2.38 & 2.31 & 1.96 & 17.53 \\
\hline 2 & 10\# left & $2.64 \times 2$ & $2.62 \times 2$ & 2.31 & 2.15 & 1.62 & 16.58 \\
\hline 3 & East 13\# upgoing & $2.57 \times 2$ & $1.91 \times 2$ & 2.07 & 2.14 & 2.01 & 15.19 \\
\hline 4 & East 13\# downgoing & $2.54 \times 2$ & $2.07 \times 2$ & 2.03 & 1.96 & 1.69 & 14.89 \\
\hline 5 & West 13\# upgoing & $2.66 \times 2$ & $2.40 \times 2$ & 2.35 & 2.44 & 1.92 & 16.83 \\
\hline 6 & West 13\# downgoing & $2.53 \times 2$ & $2.24 \times 2$ & 2.31 & 2.48 & 2.00 & 16.32 \\
\hline 7 & 1\# upgoing & $2.94 \times 2$ & $2.82 \times 2$ & 2.29 & 2.88 & 2.11 & 18.80 \\
\hline 8 & 1\# downgoing & $3.36 \times 2$ & $2.59 \times 2$ & 2.28 & 2.74 & 2.25 & 19.16 \\
\hline 9 & 2\# inner circle & $2.66 \times 2$ & $2.55 \times 2$ & 2.68 & 3.46 & 2.24 & 18.80 \\
\hline 10 & $2 \#$ outer circle & $2.38 \times 2$ & $2.79 \times 2$ & 2.69 & 3.42 & 1.89 & 18.33 \\
\hline 11 & 5\# upgoing & $2.31 \times 2$ & $2.73 \times 2$ & 2.16 & 1.95 & 1.59 & 15.79 \\
\hline 12 & 5\# downgoing & $2.51 \times 2$ & $2.92 \times 2$ & 1.75 & 2.13 & 1.65 & 16.38 \\
\hline 13 & Ba-Tong upgoing & $2.79 \times 2$ & $2.48 \times 2$ & 1.96 & 1.87 & 1.32 & 15.68 \\
\hline 14 & Ba-Tong downgoing & $2.89 \times 2$ & $2.45 \times 2$ & 1.91 & 1.88 & 1.52 & 16.00 \\
\hline
\end{tabular}

TABLE 8: Percentiles of track quality quantities over all the 14 tracks as a whole.

\begin{tabular}{|c|c|c|c|c|c|c|c|}
\hline$\#$ & Percentile & Surface & Alignment & Gauge & Cross level & Twist & TQI \\
\hline 1 & 70th & $2.18 \times 2$ & $1.97 \times 2$ & 1.36 & 1.61 & 1.44 & 12.70 \\
\hline 2 & 75th & $2.29 \times 2$ & $2.11 \times 2$ & 1.48 & 1.76 & 1.51 & 13.55 \\
\hline 3 & 80th & $2.41 \times 2$ & $2.26 \times 2$ & 1.65 & 1.91 & 1.61 & 14.51 \\
\hline 4 & 85 th & $2.55 \times 2$ & $2.43 \times 2$ & 1.88 & 2.13 & 1.73 & 15.70 \\
\hline 5 & 90th & $2.70 \times 2$ & $2.63 \times 2$ & 2.25 & 2.49 & 1.87 & 17.27 \\
\hline
\end{tabular}

on the track quality measurement data for the recent three years, the track quality standard recommendations were proposed. The recommendations have been approved by Road Administration of Beijing Municipal Commission of Transport and put into practice.

The proposed method for determining overall track quality standards can be applied to other subways if track condition measurement data of their track geometry cars are available.

\section{Conflict of Interests}

The authors declare that there is no conflict of interests regarding the publication of this paper.

\section{Authors' Contribution}

Reng-Kui Liu and Peng Xu contributed equally to this work.

\section{Acknowledgments}

This research was funded by Beijing Jiaotong University under Grant 2014RC003 and by Road Administration of Beijing Municipal Commission of Transport under Grant T11L00170. Beijing Metro provided track quality measurement data by its track geometry car GW-01 to this research. Mr. Yong Li and Mr. Jian Huang of Beijing Metro shared their knowledge regarding the data from GW-01. Mrs. Jian Yuan and Mr. Ke-Qi Ni of Beijing Metro and Mr. Mei Sun of China Railway Corporation shared their experiences about track quality management.

\section{References}

[1] A. S. Huzayyin and H. Salem, "Analysis of thirty years evolution of urban growth, transport demand and supply, energy consumption, greenhouse and pollutants emissions in Greater Cairo," Research in Transportation Economics, vol. 40, no. 1, pp. 104-115, 2013.

[2] Wikipedia. List of Metro Systems, 2014, http://en.wikipedia.org/ wiki/List_of_metro_systems.

[3] R. Liu and P. Xu, Track Irregularity Condition Indices for Beijing Metro, Road Administration of Beijing Municipal Commission of Transport, Beijing, China, 2012.

[4] The Ministry of Railways of the People's Republic of China, Railway Line Maintenance Regulations, China Railway Press, Beijing, China, 2010.

[5] CEN, Railway Applications-Track-Track Geometry Quality, in Part 1: Characterization of Track Geometry, CEN, Brussels, Belgium, 2008.

[6] C. Esveld, Modern Railway Track, Delft University of Technology, Delft, The Netherlands, 2001.

[7] FRA, Federal Railroad Administration Track Safety Standards Compliance Manual, Federal Railroad Administration, Washington, DC, USA, 2008. 
[8] The Ministry of Railways of the People's Republic of China, New Railway Line Design Interim Provisions for Mixed Passenger and Freight Traffic under $200 \mathrm{~km} / \mathrm{h}$, China Railway Press, Beijing, China, 2006.

[9] General Administration of Quality Supervision Inspection and Quarantine of the People's Republic of China and Ministry of housing and urban-rural development of the people's republic of china, Metro Design Interim Provisions, Architecture \& Industry Publishing House of China, Beijing, China, 2013.

[10] P. Xu, Q. Sun, R. Liu, R. R. Souleyrette, and F. Wang, "Optimizing the alignment of inspection data from track geometry cars," Computer-Aided Civil and Infrastructure Engineering, 2014.

[11] P. Xu, Q.-X. Sun, R.-K. Liu, and F.-T. Wang, "Key Equipment Identification model for correcting milepost errors of track geometry data from track inspection cars," Transportation Research Part C: Emerging Technologies, vol. 35, pp. 85-103, 2013.

[12] P. Xu, R. Liu, Q. Sun, and L. Jiang, "Dynamic-time-warpingbased measurement data alignment model for condition-based railroad track maintenance," IEEE Transactions on Intelligent Transportation Systems, 2015. 


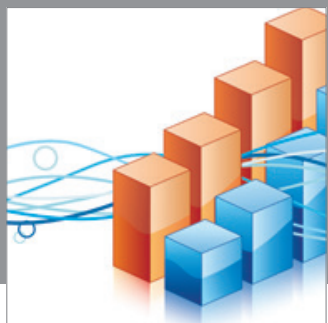

Advances in

Operations Research

mansans

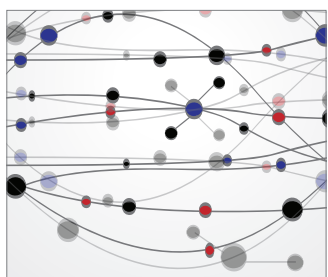

The Scientific World Journal
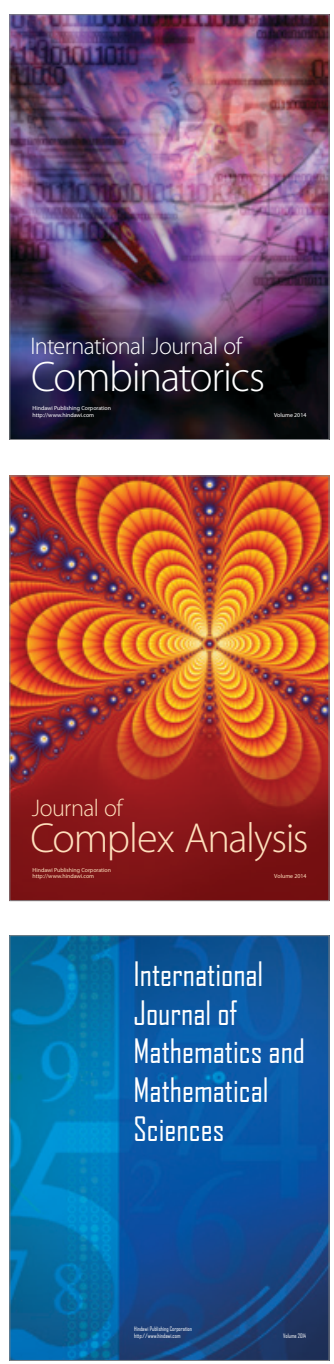
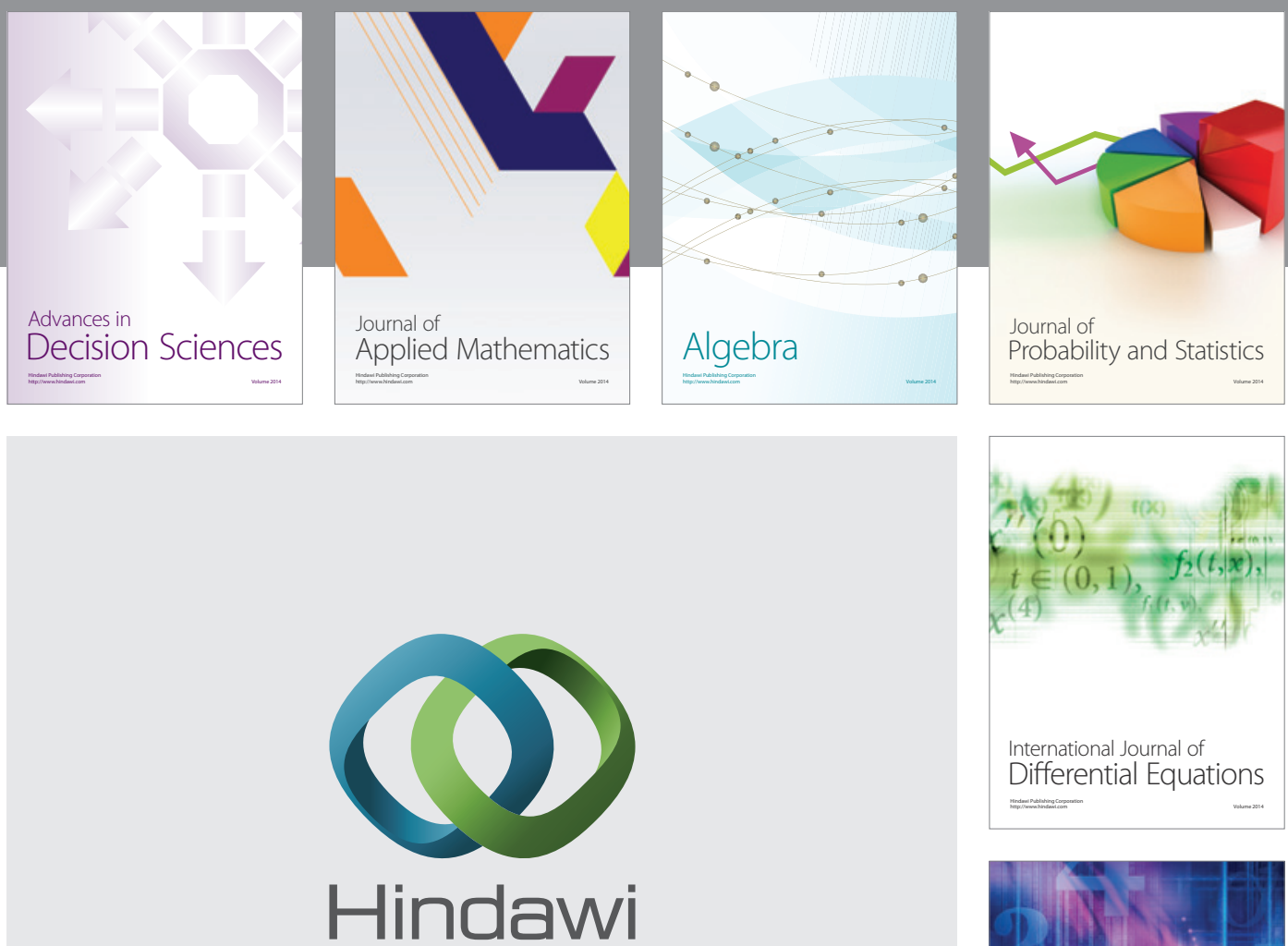

Submit your manuscripts at http://www.hindawi.com
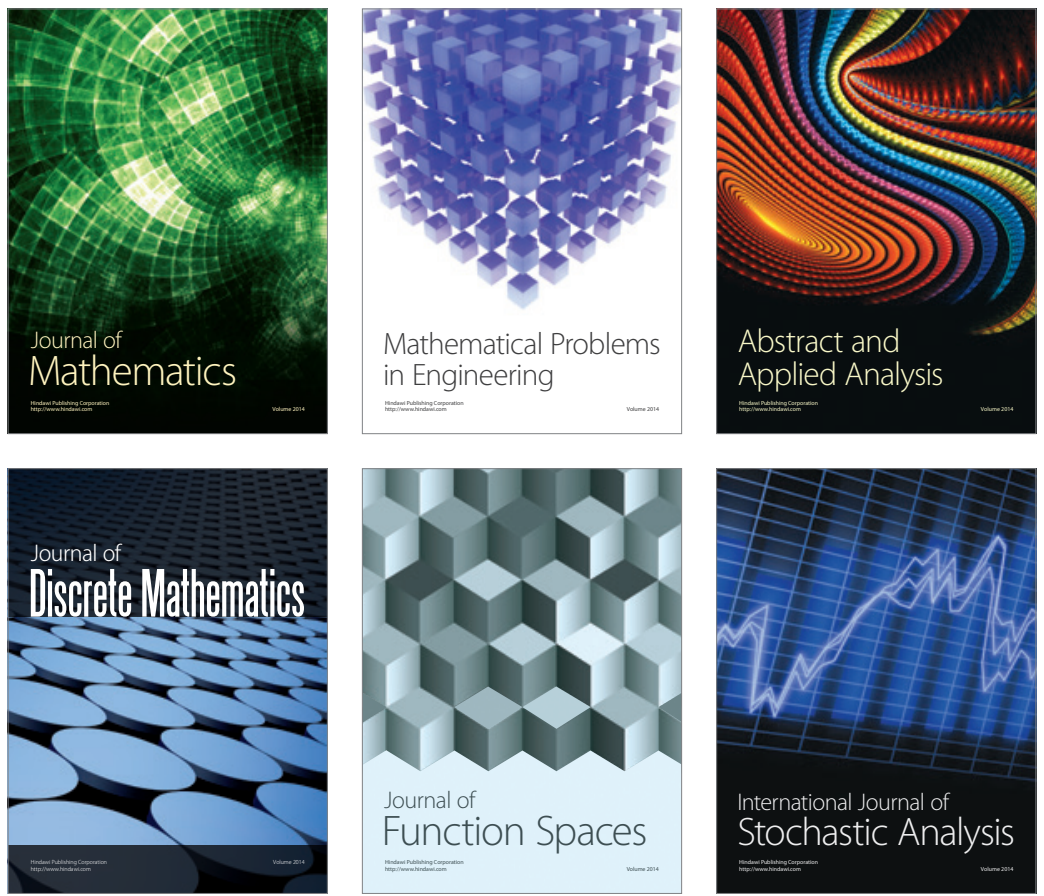

Journal of

Function Spaces

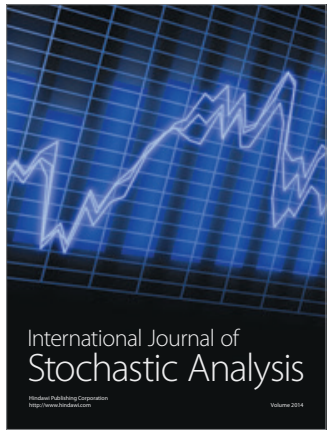

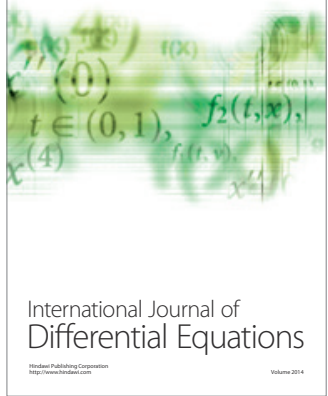
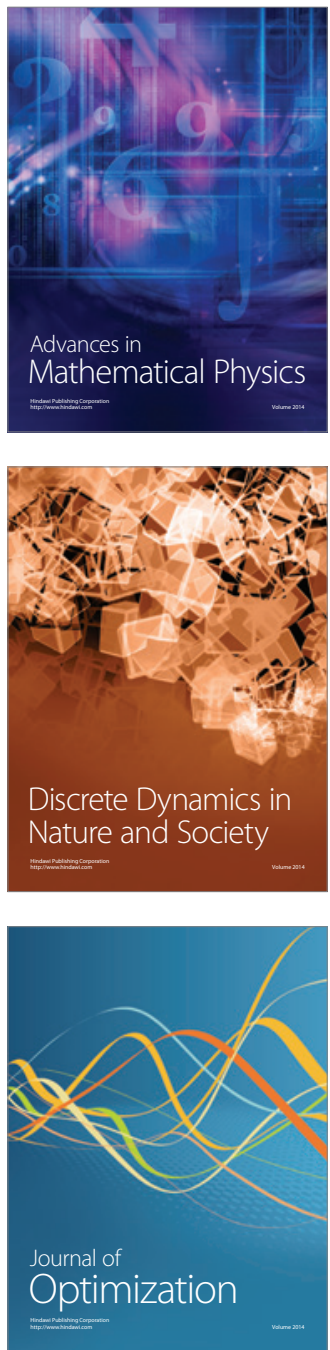